\title{
The Role of PTPN22 in Rehumatiode Arthritis and Type 1 Diabeties a Non-MHC Complex Linked
}

\author{
Fawad Akthar ${ }^{1}$, Muhammad Zeeshan ${ }^{3}$, Sajid Ali ${ }^{2}$, Faisal Nouroz ${ }^{3}$, Sara Khan ${ }^{3}$, Fazal Jalil ${ }^{2}$, , \\ Uswa Sajid $^{4}$, Hira Ikram ${ }^{5}$, Faheem Anwar ${ }^{6}$ \\ ${ }^{1}$ Department of Biotechnology, Islamic International University, Islamabad, Pakistan \\ ${ }^{2}$ Department of Biotechnology, Abdul Wali Khan University, Mardan Kpk, Pakistan \\ ${ }^{3}$ Department of Bioinformatics, Hazara University, Manshera Kpk, Pakistan \\ ${ }^{4}$ Department of Zoology, Hazara University, Mansehra Kpk, Pakistan \\ ${ }^{5}$ Department of Biochemistry, Abdul Wali Khan University, Mardan Kpk, Pakistan \\ ${ }^{6}$ Department of Genetics, Hazara University, Mansehra Kpk, Pakistan
}

Email address:

fazaljalil@awkum.edu.pk (F. Jalil)

${ }^{*}$ Corresponding author

\section{To cite this article:}

Fawad Akthar, Muhammad Zeeshan, Sajid Ali, Faisal Nouroz, Sara Khan, Fazal Jalil, Uswa Sajid, Hira Ikram, Faheem Anwar. The Role of PTPN22 in Rehumatiode Arthritis and Type 1 Diabeties a Non-MHC Complex Linked. Biochemistry and Molecular Biology.

Vol. 5, No. 3, 2020, pp. 29-36. doi: 10.11648/j.bmb.20200503.11

Received: September 30, 2019; Accepted: June 30, 2020; Published: October 30, 2020

\begin{abstract}
Rheumatoid Arthritis and Type One Diabetes are devastating clinical conditions characterized by the Autoantibody production against self, affecting up to $5 \%$ of population which, ultimately leads to a destruction of cartilage, bones and, insulin; producing Beta cells of Pancreas. As both environmental and genetic factors contribute to these conditions $(50-60 \%)$. The focus of our review is to enlist that either combined evidence shows the association of Protein Tyrosine Phosphatase Non-receptor type 22 C1858T Polymorphism with these two devastating conditions are not. A minor but most prominent allele of Protein Tyrosine Phosphatase Non-receptor type 22 gene, W620, plays a crucial role in the disease initiation process. The web sources we use for data collection were Google Scholar, PubMed, Online Mendelian Inheritance in Man, and Science Direct. At the same time, the Mesh term of our search was the role of Protein Tyrosine Phosphatase Nonreceptor type 22 gene, Single Nucleotide Polymorphism C1858T, 620W, Arg620Trp in Rheumatoid Arthritis and Type One Diabetes. The data set was consist of 210 research articles, which reviewed critically; 73 highly related articles were selected for data extraction to give knowledge to the reader at a glance. Also, taking into account the futuristic perspective for researchers that need further evaluation and will ultimately lead to drug development that will aid enhancement in therapeutics.
\end{abstract}

Keywords: Autoimmune, Devastating, Evidence, Glance, Insulin, Mesh, Monogenic, Prominent

\section{Introduction}

Almost every disease has some genetic background as well as some unique features upon which the future research methods are designed. Some disorders are complex (involves many factors, both genetic and environmental), while others are simple monogenic diseases following the Mendelian pattern of inheritances. On the other hand, some simpler clinical conditions like fever are caused by the accumulation of pyrogenic protein that alters the thermostat of the hypothalamus higher. The best example of multifactorial diseases is an autoimmune disease that involves both environmental and genetic factors [1]. In autoimmune diseases, self-tolerance of the body is lost, so it produces autoantibody, which mediates cells and tissue destruction and is termed as immune-mediated body destruction because the body loses the integrity to identify biological marker of its own cells and tissues [2]. If we look at the genetic background of autoimmune diseases, it shows interconnected Pathophysiological pathways and co-occurrence in familial segregation [3].

Autoimmune diseases affect about $5 \%$ of the population. 
The basic theme of disease initiation is not fully understood; however, genetic factors are playing a crucial role. Their consideration in future studies is highly essential $[4,5]$. Different studies have shown the genetic basis of autoimmune diseases. Several genes have been found in association with various diseases, even when a single nucleotide polymorphism occurs in them (SNP) [6]. At the genetic level susceptibility to autoimmune diseases revolve around MHC complex although there is number of non-MHC linked gene. Major histocompatibility complex (MHC) is a group of genes that is code for MHC antigen. Both major and minor alleles of the MHC complex are collectively called transplantation antigen. The expression profile of alleles in the MHC complex makes an organism susceptible to a large number of autoimmune diseases [7]. The advancement in molecular genetics and the development of hight throughput methods for investigation of causing factors of diseases have led to the identification of several genes and loci in both Rheumatoid Arthritis and T1D. Some of these genes are disease-specific like CD2/CD58, TNFAIP3, PRDM1, BLK involved in Rheumatoid Arthritis but is not responsible for T1D.

Similarly, PTPN2, IL2RA, IL10 is involved in T1D but is not responsible for Rheumatoid Arthritis. In addition some genes and loci are shared by these two devastating clinical conditions IL2/IL21, PTPN22 [6]. Cytotoxic T Lymphocyes Antigen (CTLA4) act as T-cell activator and deactivator and has been assoicated TID, Rheumatoid Arthritis, autoimmune thryiod diseases (AITD) and graves disease.

Despite the above MHC complex linked autoimmun diseases. There are a lot of genes that is not connected with the MHC complex. However, these genes play an essential role in the susceptibility of an individual to exposer to autoimmune diseases, like cytoplasmic protein tyrosine phosphatase Non-receptor type 22 ( PTPN22) gene.

Cytoplasmic protein tyrosine phosphatase non-receptor type22 (lyp) is encoded by PTPN22 gene, which is found on chromosome 1p13.3-13.1 about 57898bp in length that encodes a protein of 807 amino acid residue having a molecular weight of about $91705 \mathrm{Da}$. PTPN22 gene consists of 24 expressible regions (exons) having 21 transcriptomics variants (transcripts) [8]. Alleles of PTPN22 (R620 and W620) are found in association with increased risk of multiple autoimmune diseases like systematic lupus ertheromytoses (SLE), Rheumatoid arthritis (RA), graves diseases, hashmitho thyroiditis, Crohn disease, primary sclerosing cholangitis, type 1 diabetes (TID) and others [9-17]. The main focus of the review article is the role of PTPN22 in autoimmune diseases and how its allele act as susceptibility agent for individual toward Rheumatoid Arthritis and T1D.

\section{PTPN22 as on and off Switch for T-cell}

PTPN22 is also known as (hematopoietic cell proteintyrosine phosphatase 70Z-PEP, lymphoid phosphatase, lymphoid-specific protein tyrosine phosphatase, PEP, PESTdomain protein tyrosine phosphatase non-receptor type 22). It is a family of protein usually that receives signals from the external environment which direct cell either to divide, grow or to mature and take specialized action. Furthermore, PTPN22 is a protein involved in T-cell signaling, thus play an important role in body protection against foreign attack. As we know, signals are required across the T-cell receptor (TCR) for the development of T-cell in the thymus region for self-tolerance or self-identification and lymphoid organs. In order to maintain homeostasis in the immune response, a balance phosphorylation and dephosphorylation is required. The cytoplasmic protein tyrosine phosphatase (PTPN22) act as a negative controller of signals transduction across TCR for inhibition of key signaling molecules and is also involved in dephosphorylating the positive regulatory targeted protein of C-SRC family kinases i-e is FynT and Lck [18, 19]. More simply protein phosphatases (PTPs) dephosphorylate the cellular protein which is being phosphorylated thus controlling initiative intensity of T-cell by acting on zap70 protein of $70 \mathrm{kda}$ and lyphoid specific protein kinases (lyp) [20-22].

\section{Variations in PTPN22 as a Risk Factor of Autoimmune Diseases}

As we have discussed earlier, Protein tyrosine phosphatase non-receptor type 22/lyp protein has 21 transcripts, produced during alternative splicing, may a particular exon can be connected with any other exon to form a mature mRNA. Based on alternative splicing phenomena, the isoform may share some sequences with each other, but not all. The PTPN22 gene has 10 isoforms while some paper and book shows 11, which is responsible for coding of functional proteins. Human genome annotation and GWAS study focus on two allele recently identified (i-e lyp-1 and lyp2). lyp-1 encodes amino-terminal of protein tyrosin phosphates (PTP) domain, a carboxy-terminal containing proline rich motifs P1, P2, P3, P4 and an unknown functional middle region. On the other hand, lyp-2 have a short terminal end containing only $\mathrm{P} 1$ motif $[23,24]$. The $\mathrm{P} 1$ domain of PTPN22 gene is responsible for binding with $\mathrm{SH} 3$ domain of Csk family and thus inhibits the spontaneous T-cell activation or doing down regulation of T-cell $[9,25]$. The detail picture is shown in figure 1.

Every change that occurs in PTPN22 gene may not be responsible for the autoimmune disorder may be the SNP protect against autoimmune diseases like varient R263Q in exon 10 that alter the catalytic domain reducing the phosphatase activity which protects against Rheumatoid Arthritis, ulcerative colitis, SLE thus is not responsible for predisposition of an individual to autoimmune diseases [2628]. While on the other hand SNP at position no, C1858T in exon 14 that changes arginine amino acid residue to tryptophan R620W occur in lyp, it causes weak bonding or either inhibit binding of C-Src kinases with proline rich domain of tyrosine phosphatase / lyp [24, 29]. The down regulatory function of TCR through PTPN22 is lost and is 
now responsible for a number of non-HLA linked autoimmune disease. The SNP in Lyp/PTPN22 gene may be acting as a predisposing factor for Rheumatoid Arthritis, JIA, TID, and SLE (Figure no 1), which we will discuss in this review.

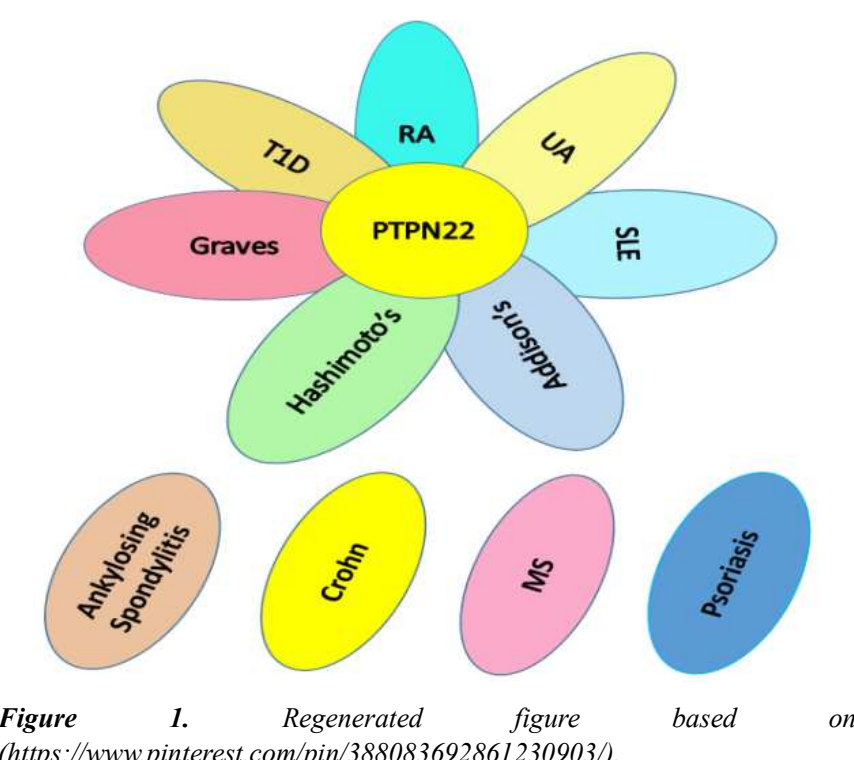

(https://www.pinterest.com/pin/388083692861230903/).

\section{PTPN22 as Predisposition Agent to Rheumatoid Arthritis}

Rheumatoid arthritis is a cell-mediated systematic chronic inflammatory disease of joints, effecting females and males at ratio of 3:1. Common symptoms include pain swelling and stiffness in joints. At the early stages small joints are mainly effected like joints of phalanges and later on large joints like pelivc, pectoral, and knee. Joints are usually effected in a symmetrical pattern. A lote of studies are present on the role of PTPN22 gene in rheumatoid arthritis some of which are the following:

Two sample set was selected from white American population in which sample set 1 was consist of 475 RFpositive case whose condition meet with the criteria of american collage of rehumatology and 475 control each of controls was matched with case on basis of sex ethenicty. [30] However, the control was taken from a healthy individual with no medical history of Rheumatoid Arthritis. On the other hand, sample set 2 was consist of 661 cases and 1322 controls, which was a subset of 2000 control, 2 controls was matched with a single randomly chosen case on the basis of sex, ethnicity, age samples was taken from north American rehumatiod arthritis consortium. PTPN22 sequencing was done by the selection of 48 patients of genotypes showing all of the three alleles of (CC, CT, TT). They were resequenced by using standard PCR 96 well. Along with these for better accuracy, they selected SNP through program Redigo, Allele specific PCR primer were used genotyping was done through custom software accuracy predefined $>98.8 \%$. At last through haplotype analysis they found 10 alleles having frequency greater than $1 \%$ in white American population. The result shows that individuals carrying R620 allele shows no association with Rheumatoid Arthritis. In addition allele $620 \mathrm{~W}$ is a risk factor and is greatly associated with rehumatoide arthritis prdisoposing individuals to a lot of other autoimmune diseases because of the patient with rehumatiod arthritis showing an increase in the T neucleotide.

Furthermore Tokyo Women's Medical University Japane included 4000 registered rehumatiod arthritis patients. DNA was taken from 1284 patients out of these 1284, 1128 samples were randomly selected [31]. In these samples, $88 \%$ of patient was Rheumatoid Arthritis positive and was female, mostly about $82.6 \%$ and 455 matched control for sex, age, ethnic, and geography was taken from Pharma SNP Consortium. Other than R620W functional SNP they selected 8 other SNP for allowing the haplotype detection of HapMap project (release 19 October 2005). They use another type of SNP3 (rs3765598) which was in absolut linkage disequilibrium (LD) with SNP rs3789604. They finally selected 9 SNP spinning $45 \mathrm{~Kb}$ over the selected PTPN22 gene. Statisticaal power was greater than 90\% alonge with 5\% Significans and was calculated using a web power calculator. Finally genotyping was done by Taqman flurogenic 5' nuclease assay. PCR was performed in dual 384-well gene amplification system. ABI PRISM 7900 was used for flurecence reading. Japanes study found no association of R620W allele also, the other 8 SNP was in H-W equilibrium in both patients and controls. In addition, the substituted SNP3 rs3789604 was equal in both of case and control. Also haplotype or sex analysis also reveals no association with Rheumatoid Arthritis. On the basis of these results, they declared that PTPN22 is not associated with Rheumatoid Arthritis in Japanese society.

In addition to above studies 869 patients along with 563 controls form white ethinic origin of Newzealand, the control patient was from Plenty, Wellington, Canterbury, Otago, and Southland in order to satisfy the criteria of American collage of rehumatology (ACR) 1987 [32]. Healthy controls older then 17 years were taken from Otago, Southland having no history of inflammatory diseases. The study was based on minor allele frequency 0.10 having $96.0 \%$ power to detect an effective size as previously in Rheumatoid Arthritis. They SNP genotyping was based on PCR restriction fragment length polymorphism (RFLP). Primer for both sense (5'GAACAAGTGTCAACTTTACTG-3') and antisence s (5'CTTCCTCAACCACAATAAATG-3') strand were used. Fragments of $199 \mathrm{bp}$ and 33bp were produced using enzyme Rsa I. after running the PCR product on gel was analyed under UV rediation they found $15.1 \%$ frequncy of $1858 \mathrm{~T}$ allele in patients as compared $9.9 \%$ of the control individuals. Also, they tested the interaction between the PTPN22 allele and HLA-DRB1 found no evidence for two locus under a multiplicative model.

To realize and check the reproducibility of data that either PTPN22 is associated with Rheumatoid Arthritis in Rheumatoid Arthritis cohort or not. Despite present assoication studies data. The frequency was studied in two independently collected Candian sample sets [16]. Sample set 
1 was composed of 906 patient and 603 controls from Toronto and 328 patient and 128 controls from Halifax nova scotia. The two taken cohort was similar on the bases of sex, age, and RF positivity and noduls. The genotyping was found to be $>95 \%$ through Mass ARRAY matrix- assisted laser desorption ionization-time-of-flight mass spec-trometry system. Genotypic analysis of both cohort have frequency was in H-W quilibrium. However Toronto study found Patients $(0.140)$ controls $(0.083) \mathrm{X} 2=23.0, \mathrm{P}=1.6 \times 10-6 \mathrm{OR}$ $1.80,[95 \% \mathrm{CI}] 1.41-2.30)$ significantly greater frequncey in patient than that of control but was not engouh different than that reported by Begovich et al for cases and controls. As shown in table 1 .

Table 1. Showing detail case control study of mutant PTPN22 in RA.

\begin{tabular}{|c|c|c|c|c|c|}
\hline $\begin{array}{l}\text { Details for } \\
\text { studies }\end{array}$ & Sample sets origin & Patients & Controls & SNP genotyped & Conformation of SNP \\
\hline \multirow[t]{2}{*}[30]{} & American population 1 & 475 & 475 & $\begin{array}{l}\text { Patients (48) were genotyped } \\
\text { having allele (CC, CT, TT) }\end{array}$ & \multirow{2}{*}{$\begin{array}{l}\text { CT was a risk factor and was associated with } R \text {. } \\
A>T \text { allele } \\
C T \text { was a risk factor and was associated with } R \text {. } \\
A>T \text { allele }\end{array}$} \\
\hline & American population 2 & 661 & 1322 & Same study & \\
\hline [31] & Japanese & 1128 & 455 & $\begin{array}{l}\text { SNPs }(8)+1 \text { change rs } 3765598 \\
\text { to rs3789604 }\end{array}$ & Declared no association of CT with R. A \\
\hline [32] & New Zealand & 869 & 563 & C1858T SNP (rs2476601) & \multirow{2}{*}{$\begin{array}{l}15.1 \% \text { patients } 9.9 \% \text { control } \\
\text { Patients }(0.140) \text { controls }(0.083) \mathrm{X}^{2}=23.0, \mathrm{P}= \\
\left.1.6 \times 10^{-6} \text { OR } 1.80,[95 \% \mathrm{CI}] 1.41-2.30\right)\end{array}$} \\
\hline \multirow[t]{2}{*}{ [16] } & Canadian 1 Toronto & 906 & 603 & C1858T SNP (rs2476601) & \\
\hline & Canadian 2 Halifax & 328 & 128 & Same as above same study & $\begin{array}{l}\text { Patient }\left(0.171, \mathrm{X}^{2}=3.54, \mathrm{P}=0.06\right) \text { control }(0.096, \\
\left.\mathrm{X}^{2}=0.60, \mathrm{P}=0.520\right)\end{array}$ \\
\hline
\end{tabular}

\section{PTPN22 in Type 1 Diabetes}

Diabetes is condition characterized by elevated glucose level of blood (hyperglycemia), which results due to insufficient, ineffective, abnormal insulin, or insulin resistance of targeted cell and insulin producing $\beta$-cell distruction. High blood glucose level due to diabetes can result in other life threatening complications like nerves damage blood vessels and blood organs. Type 1 diabetes is totally dependent on insuline, which we will discuss in detail.

According to the world health organization report (WHO) in 1995 about $4 \%$ of the world's population is affected by diabetes and is expected to increase upto $5.4 \%$ in 2025 [33]. About $10 \%$ of the total diabetic population is effected with T1D. Type 1 diabetes is an autoimmune-mediated attack/disorder in which $\beta$ cell in pancreas is damaged resulting in lack of insuline in the body. The most common symptoms include frequent urination/polyurea blurred vision and weightloss e-t-c. eitology of the disease shows a decrease with unrealatedness but frequncey is $50 \%$ in monozygotic twins [34, 35]. With exception, PTPN22 a lot of other HLA class 2 gene show susceptibilty in exploser of individual to T1D [36, 37].

Furthermore polymorphism of Arg620Trp in PTPN22 gene may be the cause of T1D. [9] Showed that this substitution is involved in reducing the tyrosine kinases interaction, thus leading to pathoginic T-cell responces. T1D occure at earley stages of life by the formation of $\beta$-cell-specific immunological responses which later on results in diseases condition among individuals. Diseases is initiated with Tlympocytes infilteration in pancreatic islets, as shown by some histological and other functional studies. Which reflects back in formation $\beta$-cell specific autoantibody and causes distruction of $\beta$-cell resulting in low quantity of insulin production. This can be used as a useful tool for the prediction of diseases, however understanding diseases mechanism, it is hard to explore genetic factors that is responsible for emergence of diseases because a number of genes are involved in disease initiation [38-42].

Two sample set was analyzed, Sample set 1 was from Czech patient having 372 patients that have devolped T1D at the age of 15years which was compared with 400 controls [43]. The subjects composed of 188 males and 184 females was diagnosed on the basis of WHO criteria.

Sample set 2 was composed of 160 Azerbaijan patients composed of 81 males and 79 females diagnosed under WHO glycemic criteria having T1D at an age under 19 years. Compared with 271 controls composed of 79 males and 192 females.

They determine the genotype of three SNP i-e rs2476601 $\mathrm{G}=>\mathrm{A}$ on forward and $\mathrm{C}=>\mathrm{T}$ on the reverse strand at position +1858 which was related to translational start necleotide resulting in R620W substitution, rs2488457 SNP resulting substitution of $C=>\mathrm{G}$ at postion -1123 on forward strand of promoter region related to translation start neucleotide and rs1217412 SNP which is substitution of $A=>G$ at position +2740 related to un transalated region of translational start neucleotide.

Statistically, the allelic frequency was in hardy-weingberg equlibrium and was determined by gene counting, while Hardy-weingberg was checked by comparing observed to expected genotypic frequencies. Association between the T1D and SNP was shown by odd ratio along with $95 \%$ confidence interval and was confirmed by $\mathrm{X}^{2}$-test or exact test method. Haplotype analysis was determind by expectation maximization alogrithm present in stata program 9.2 and was determined by long-linear modelling.

The results they obtained from the Czech patient was found that all of the minor allele of the SNPs at position $1123 \mathrm{C} / \mathrm{G}$ R620W and $+2740 \mathrm{~A} / \mathrm{G}$ were significantly associted with T1D. However, the association was strongest for $620 \mathrm{~W}$ 
among these three SNP as compared to the controls. Haplotype analysis determined that only W620 allele showing association with T1D. No association was found in haplotypes containing 3'-UTR polymorphism and R620 allele was neutral to the condition of the disease showing no difference in gender base.

While on the other hand the risk allel (W620) was associated with the T1D in the Azeri patients as compared with T1D that is $8(5 \%)$ cases and $2(0.74 \%)$ in controls, however the remaining two allele was not associated with T1D.

\section{Results and Discussion}

Reproducibility was checked by conduction of another study was conducted from the Czech population southeast but had slight differences [44]. They have included 396 patients and genotype the SNP with in the gene PTPN22 at position $\mathrm{C} 1858 \mathrm{~T}$ beside this 1178 matched controls with no history of T1D was taken from north central Florid, they also include causcasian families from Human Biological Data interchange the patients was diagnosed according to the criteria of national Diabetes Data Group. clinical information of the patient is present in [45-47].

Genotyping was performed using Taq polymerase enzyme both forward and reverse primer PTPN22_rs247_F1 (5'ACTGATAATGTTGCTTCAACGG) and PTPN22_RS247_R1 (5'TCACCAGCT TCCTCAACCAC). A fragment of 218 base pairs was amplified containing SNP C1858T within the coding region. After amplification, the PCR products were separated on $2.5 \%$ agrose gel after treating with RsaI for overnight at $37^{\circ} \mathrm{C}$ ethidum bromide were used for visualization. Upon application of RsaI the normal fragments was digested into two, leaving the polymorhism containing fragment (1858T) unchanged and was not digested by RsaI because of mutation. Linkage disequlibrium test was performed by $\mathrm{X}^{2}$ technique in order to evaluate $(50 \%)$ transmission from heterozygous parents to affected offspring.

The results frequencies were as such that homozygous genotype $(\mathrm{C} / \mathrm{C})$ has $83.5 \%$ controls and was higher as compared to T1D patient $(73.2 \%)$, homozygous $(\mathrm{T} / \mathrm{T})$ have $0.7 \%$ in controls and $2.3 \%$ in T1D patient furthermore heterozygous genotype $(\mathrm{C} / \mathrm{T})$ have frequencies $15.8 \%$ in controls and $24.5 \%$ in patients.

Other than the above studies [48], they have selected four sample sets, samples set $1^{\text {st }}$ was composed of 298 patients of T1d from central Italy and 360 controls from same ethnic group of Italy. $2^{\text {nd }}$ sample set was from Rome (Diabetology unit, university of Rome Tor vergata) consist of 216 patients and 271 controls from the same ethnic group. Also, 82 patients and 89 controls were taken from the Chieti, patients were from the (Diabetology unit of the Chieti University) the patient was diagnosed was based upon the WHO criteria of Insulin-dependent diabetes mellitus (T1d). Inform written consent was taken from children's parents for their participation in the study. Information was provided for
Rome population and was found that $66.1 \%$ of patients were positive for anti-islet antigen-2A and $47.1 \%$ for anti-insulin antibody also they found that $64.1 \%$ were positive for ant glutamic acid decarboxylase (GADA) autoantibody.

DNA was obtained from blood extracted with Venipuncture under the use of MagNA Pure LC instruments the evaluation of SNP (C-T) at position 1858 using RFLP, based PCR technique. The PCR master mix details is present in original article [48]. After performing the amplification reaction, the polymorphism was confirmed by the application of $\mathrm{XcmI}$ restriction endonucleases because the transition of $\mathrm{C}>\mathrm{T}$ at 620 codon develops restriction site for XcmI. The product was separated on 3\% agarose gel under the use of Radio ligand assay (DRG Instruments GmbH, Marburg/ Lahn, Germany) in order to identify the antibody against GADA, PTPs and insulin.

The allelic frequency in their study revealed that the frequency of T1858 allele was more in patients as compared to the controls, also they suggested that the tendency of this allele to be greater in males than that of females in both cases and controls but overall the allele was not associated with gender. In addition they kept the odd ratio for both patients and controls were 2.29, the results for Rome patients in consideration of both gender were: males control $6.8 \%$ and $14.0 \%$ in patients, females control $2.9 \%$ and $8.3 \%$ patients, also in Chieti population $7.4 \%$ in male controls $13.8 \%$ in patients and $2.9 \%$ in females controls and $15.1 \%$ in female patients.

Another study have selected 528 multitudinous families 145 from French origin 159 from Danish and 224 from U-S$\mathrm{A}$, in the multiplex Danish families at the time of sampling antglutamic acid Decarboxylase-65 along with protein tyrosine phosphatase (insuliminoma-associated protein 2 [IA2]) autoantibodies was adjudged [49]. Also 241 simplex families, which were previously described $[50,51]$ and 161 (102 Danish, 59 French) families with 1 affected child and parent were taken in account. The case-cohort was composed of 892 T1D Diabetic patients from French and 456 controls from same ethnic group. Furthermore, autoantibodies peculiar/especial to other organs, including thyroperoxydase, antigastric parietals cell, antiggliadin, antitrasglutaminase was also obtainable from sample subset in addition family history of T1D and other like R. A, Celiac, autoimmune thyroid was also acquirable from the sample set.

Genotyping of SNP C1858T within a gene of PTPN22 was accomplish using TaqMan assay or PCR-RFLP, with selfimage results were procure/realize on coequal genotyping in subsets of 190 DNA selection. In addition, SNP rs3789604 and rs2488457 were achieved using the same assay. Also, HLA regions and INS-23/HphI were also performed and were in $\mathrm{H}-\mathrm{W}$ equilibrium. Statistical analysis in account of PTPN22 they carry out transmission disequilibrium test for risks relating HLA-DRB1 (DR3/DR4, DR34+, DR34-) INS+(liable), INS-(non-liable) through ANALYZE. In addition, four stratification was also prosecuted that was the presence of T1D at initial or second degree along with absence or presence of autoantibodies against specific organs 
association analysis were carried out using double-sided $\mathrm{X}^{2}$ test. Also for haplotype association Haplo. Stats package was used furthermore ANOVA and logistic regression was achieved using STAT-VIEW but was kept limited to Danish multitude families.

Results they first carry out transmission disequilibrium test of 930 multitude and simplex families from Denmark France and U.S and sort the over transmission of T allele (C1858T) to T1D patients (339 vs $249,57.7 \% \mathrm{P}=0.0002)$ with no attestation of heterogeneity to the family origin and transmission deformation to unaffected siblings. Furthermore, they commit a case control collaboration study of susceptibility allele C1858T SNP in French population and found higher frequency of $\mathrm{T}$ allele in patient $(29.6 \%)$ as compared to controls $\left(17.9 \% \mathrm{P}=4 \times 10^{-6}\right)$ again there was no affiliation of $\mathrm{T}$ allele between patients stratified on basis of gender HLA-DR, INS risk and heterogeneity defending on family background of T1D. Further details are present in the original paper. Details of studies is shown in Table 2.

Table 2. Shows assiociation of PTPN22 in T1D in various population.

\begin{tabular}{|c|c|c|c|c|c|}
\hline $\begin{array}{l}\text { Details for } \\
\text { study }\end{array}$ & $\begin{array}{l}\text { Sample sets } \\
\text { origin }\end{array}$ & Patients & Controls & SNP genotyped & Conformation of SNP \\
\hline \multirow[t]{2}{*}{ [43] } & Czech & 372 & 400 & $\begin{array}{l}\text { rs2476601 rs2488457 } \\
\text { rs } 1217412\end{array}$ & All of SNPs was significantly associated with T1D \\
\hline & Azeri & 160 & 271 & As above same paper & $(5 \%)$ cases and $2(0.74 \%)$ in controls \\
\hline [44] & Czech & 396 & 1178 & - SNP C1858T & $\begin{array}{l}(\mathrm{C} / \mathrm{C}) 83.5 \% \text { controls and }(73.2 \%) \mathrm{T} 1 \mathrm{D} \text { patient, }(\mathrm{T} / \mathrm{T}) 0.7 \% \text { controls } \\
\text { and } 2.3 \% \text { patient }(\mathrm{C} / \mathrm{T}) 15.8 \% \text { controls and } 24.5 \% \text { patients. }\end{array}$ \\
\hline \multirow[t]{2}{*}{ [48] } & Rome & 216 & 271 & $\begin{array}{l}\text { SNP }(C-T) \text { at position } \\
1858\end{array}$ & $\begin{array}{l}\text { males controls } 6.8 \% \text { and } 14.0 \% \text { in patients, females controls } 2.9 \% \\
\text { and } 8.3 \% \text { patients }\end{array}$ \\
\hline & Chieti & 82 & 89 & Same as above & $\begin{array}{l}7.4 \% \text { in male controls } 13.8 \% \text { in patients and } 2.9 \% \text { in females controls } \\
\text { and } 15.1 \% \text { in patients }\end{array}$ \\
\hline [49] & French & 892 & 456 & SNP C1858T & patient $(29.6 \%)$ as controls $\left(17.9 \% \mathrm{P}=4 \times 10^{-6}\right)$ \\
\hline
\end{tabular}

\section{Conclusion and Futuristic Hypothesis}

Keeping in mind the above mention studies it is clear that PTPN22 gene that act as a down regulator of Immune system by dephosphorylating the recently phosphorylated proteins by kinases family. Although when a single nucleotide change occurs in this gene, the dephosphorylation function of this gene is either dampens or inhibited and at last results in the formation of pathogenic antibodies against body own organs that causes cell-mediated body destruction. The major role in autoimmune diseases is played by the minor allele W620 which results due to SNP at position 1858 causes the substitution of $\mathrm{C}=>\mathrm{T}(\mathrm{C} 1858 \mathrm{~T})$ and is confirmed by the accumulation of the higher amount of $\mathrm{T}$ allele in samples as mention in both of above studies. Various approaches in this area are present, including gene silencing through enzymes that causes Cleavage in this gene so the resultant proteins is not formed, also PTPN22 is also being silenced by insertion of homologs of gene (gene co-repression phenomena). Different approaches to this area are being achieved using mice models by inserting homolog W619 which is homolog of LYP R620W of human this study imply that diseases variant protein is intending to repaid degradation resulting in loss of function. The highly noteworthy effect of this study found the assemblage of effector memory T-cell and their higher activity in the knocked out mice models than that of wild type; however, this deficiency leads to splenomegaly and Lymphadenopathy in aged mouse models without production of autoreactive antibody. [52] suppress the PTPN22 disease variant R620W and found that the severity of the disease may be reduced [53, 54]. Also, the protein formed by diseases variant of PTPN22 is Prone to degradation. So our main idea is focused upon the silencing of PTPN22 through the insertion of homolog through Nanocarrier termed as a liposome. Which is being used in recent years as Nano-carrier for Drugs delivery and is capable of carrying the gene of interest, but this hypothesis needs further evaluation. In addition, the basic point here is that the liposomes is digested by white blood cell. It can be used to deliver our homolog of disease variant R620W in order to suppress the activity PTPN22, but problem here is that PTPN22 silencing is not in practice in Humans. Studies suggest that silencing of PTPN22 is responsible to avoid formation of auto reactive antibodies and is being used in treatment of T1D in Transgenic produced T1D mice and was conformed that mice was recover from T1D.

\section{References}

[1] Hensvold, A. H., et al., Environmental and genetic factors in the development of anticitrullinated protein antibodies (ACPAs) and ACPA-positive rheumatoid arthritis: an epidemiological investigation in twins. Annals of the rheumatic diseases, 2015.74 (2): p. 375-380.

[2] Moosavi, M.-S. and H. Barati, Salivary gland performance in autoimmune diseases: review and meta-analysis. Acta Clinica Belgica, 2018: p. 1-7.

[3] Kridin, K., et al., Ulcerative colitis associated with pemphigus: a population-based large-scale study. Scandinavian journal of gastroenterology, 2017. 52 (12): p. 1360-1364.

[4] Marrack, P., J. Kappler, and B. L. Kotzin, Autoimmune disease: why and where it occurs. Nature medicine, 2001. 7 (8): p. 899-905.

[5] Prahalad, S., et al., Increased prevalence of familial autoimmunity in simplex and multiplex families with juvenile rheumatoid arthritis. Arthritis \& Rheumatism, 2002. 46 (7): p. 1851-1856. 
[6] Zenewicz, L. A., et al., Unraveling the genetics of autoimmunity. Cell, 2010. 140 (6): p. 791-797.

[7] Fernando, M. M., et al., Defining the role of the MHC in autoimmunity: a review and pooled analysis. PLoS Genet, 2008. 4 (4): p. e1000024.

[8] Cohen, S., et al., Cloning and characterization of a lymphoidspecific, inducible human protein tyrosine phosphatase, Lyp. Blood, 1999. 93 (6): p. 2013-2024.

[9] Bottini, N., et al., A functional variant of lymphoid tyrosine phosphatase is associated with type I diabetes. Nature Genetics, 2004. 36 (4): p. 337-338.

[10] Criswell, L. A., et al., Analysis of families in the multiple autoimmune disease genetics consortium (MADGC) collection: the PTPN22 $620 \mathrm{~W}$ allele associates with multiple autoimmune phenotypes. The American Journal of Human Genetics, 2005. 76 (4): p. 561-571.

[11] Hinks, A., et al., Association between the PTPN22 gene and rheumatoid arthritis and juvenile idiopathic arthritis in a UK population: further support that PTPN22 is an autoimmunity gene. Arthritis \& Rheumatism, 2005. 52 (6): p. 1694-1699.

[12] Lee, A., et al., The PTPN22 R620W polymorphism associates with RF positive rheumatoid arthritis in a dose-dependent manner but not with HLA-SE status. Genes and immunity, 2005. 6 (2): p. 129-133.

[13] Orozco, G., et al., Association of a functional single nucleotide polymorphism of PTPN22, encoding lymphoid protein phosphatase, with rheumatoid arthritis and systemic lupus erythematosus. Arthritis \& Rheumatism, 2005. 52 (1): p. 219-224.

[14] Santiago, J. L., et al., Susceptibility to type 1 diabetes conferred by the PTPN22 C1858T polymorphism in the Spanish population. BMC medical genetics, 2007.8 (1): p. 1.

[15] Steer, S., et al., Association of R602W in a protein tyrosine phosphatase gene with a high risk of rheumatoid arthritis in a British population: evidence for an early onset/disease severity effect. Arthritis \& Rheumatism, 2005. 52 (1): p. 358-360.

[16] Van Oene, M., et al., Association of the lymphoid tyrosine phosphatase R620W variant with rheumatoid arthritis, but not Crohn's disease, in Canadian populations. Arthritis \& Rheumatism, 2005. 52 (7): p. 1993-1998.

[17] Velaga, M., et al., The codon 620 tryptophan allele of the lymphoid tyrosine phosphatase (LYP) gene is a major determinant of Graves' disease. The Journal of Clinical Endocrinology \& Metabolism, 2004. 89 (11): p. 5862-5865.

[18] Menard, L., et al., The PTPN22 allele encoding an R620W variant interferes with the removal of developing autoreactive B cells in humans. The Journal of clinical investigation, 2011. 121 (9): p. 3635-3644.

[19] Zhang, J., et al., The autoimmune disease-associated PTPN22 variant promotes calpain-mediated Lyp/Pep degradation associated with lymphocyte and dendritic cell hyperresponsiveness. Nature genetics, 2011. 43 (9): p. 902907.

[20] $\mathrm{Wu}, \mathrm{J}$., et al., Identification of substrates of human proteintyrosine phosphatase PTPN22. Journal of Biological Chemistry, 2006. 281 (16): p. 11002-11010.

[21] Stanford, S. M. and N. Bottini, PTPN22: the archetypal non-
HLA autoimmunity gene. Nature Reviews Rheumatology, 2014. 10 (10): p. 602-611.

[22] Brownlie, R. J., et al., Lack of the phosphatase PTPN22 increases adhesion of murine regulatory $\mathrm{T}$ cells to improve their immunosuppressive function. Sci. Signal., 2012. 5 (252): p. ra87-ra87.

[23] Diaz-Gallo, L.-M. and J. Martin, PTPN22 splice forms: a new role in rheumatoid arthritis. Genome medicine, 2012. 4 (2): p. 1 .

[24] Ronninger, M., et al., The balance of expression of PTPN22 splice forms is significantly different in rheumatoid arthritis patients compared with controls. Genome medicine, 2012. 4 (1): p. 1 .

[25] Begovich, A. B., et al., A missense single-nucleotide polymorphism in a gene encoding a protein tyrosine phosphatase (PTPN22) is associated with rheumatoid arthritis. The American Journal of Human Genetics, 2004. 75 (2): p. 330-337.

[26] Stanford, S. M., T. M. Mustelin, and N. Bottini. Lymphoid tyrosine phosphatase and autoimmunity: human genetics rediscovers tyrosine phosphatases. in Seminars in immunopathology. 2010. Springer.

[27] Rodríguez-Rodríguez, L., et al., The PTPN22 R263Q polymorphism is a risk factor for rheumatoid arthritis in Caucasian case-control samples. Arthritis \& Rheumatism, 2011. 63 (2): p. 365-372.

[28] Totaro, M. C., et al., PTPN22 1858C $>\mathrm{T}$ polymorphism distribution in Europe and association with rheumatoid arthritis: case-control study and meta-analysis. PLoS One, 2011. 6 (9): p. e24292.

[29] Bottini, N. and E. J. Peterson, Tyrosine phosphatase PTPN22: multifunctional regulator of immune signaling, development, and disease. Annual review of immunology, 2014. 32: p. 83119 .

[30] Carlton, V. E., et al., PTPN22 genetic variation: evidence for multiple variants associated with rheumatoid arthritis. The American Journal of Human Genetics, 2005.77 (4): p. $567-$ 581.

[31] Ikari, K., et al., Haplotype analysis revealed no association between the PTPN22 gene and RA in a Japanese population. Rheumatology, 2006. 45 (11): p. 1345-1348.

[32] Simkins, H., et al., Association of the PTPN22 locus with rheumatoid arthritis in a New Zealand Caucasian cohort. Arthritis \& Rheumatism, 2005. 52 (7): p. 2222-2225.

[33] King, H., R. E. Aubert, and W. H. Herman, Global burden of diabetes, 1995-2025: prevalence, numerical estimates, and projections. Diabetes care, 1998. 21 (9): p. 1414-1431.

[34] Bell, P. R., et al., KMJ.

[35] Azar, S. T., et al., Type I (insulin-dependent) diabetes is a Th1and Th2-mediated autoimmune disease. Clinical and diagnostic laboratory immunology, 1999. 6 (3): p. 306-310.

[36] Hirschhorn, J. N., Genetic epidemiology of type 1 diabetes. Pediatric diabetes, 2003. 4 (2): p. 87-100.

[37] Maier, L. M. and L. S. Wicker, Genetic susceptibility to type 1 diabetes. Current opinion in immunology, 2005. 17 (6): p. 601-608. 
[38] Gepts, W., Pathologic anatomy of the pancreas in juvenile diabetes mellitus. Diabetes, 1965. 14 (10): p. 619-633.

[39] Roep, B. O., et al., T-cell clones from a type-1 diabetes patient respond to insulin secretory granule proteins. Nature, 1990. 345 (6276): p. 632-634.

[40] Ziegler, A.-G., et al., Autoantibody appearance and risk for development of childhood diabetes in offspring of parents with type 1 diabetes: the 2-year analysis of the German BABYDIAB Study. Diabetes, 1999. 48 (3): p. 460-468.

[41] Kukko, M., et al., Dynamics of diabetes-associated autoantibodies in young children with human leukocyte antigen-conferred risk of type 1 diabetes recruited from the general population. The Journal of Clinical Endocrinology \& Metabolism, 2005.90 (5): p. 2712-2717.

[42] LaGasse, J. M., et al., Successful prospective prediction of type 1 diabetes in schoolchildren through multiple defined autoantibodies an 8-year follow-up of the Washington State Diabetes Prediction Study. Diabetes Care, 2002. 25 (3): p. 505-511.

[43] Cinek, O., et al., No independent role of the $-1123 \mathrm{G}>\mathrm{C}$ and + $2740 \mathrm{~A}>\mathrm{G}$ variants in the association of PTPN22 with type 1 diabetes and juvenile idiopathic arthritis in two Caucasian populations. Diabetes research and clinical practice, 2007. 76 (2): p. 297-303.

[44] Zheng, W. and J.-X. She, Genetic association between a lymphoid tyrosine phosphatase (PTPN22) and type 1 diabetes. Diabetes, 2005. 54 (3): p. 906-908.

[45] Marron, M. P., et al., Insulin-dependent diabetes mellitus (IDDM) is associated with CTLA4 polymorphisms in multiple ethnic groups. Human molecular genetics, 1997. 6 (8): p. 1275-1282.

[46] Luo, D.-F., et al., Confirmation of three susceptibility genes to insulin-dependent diabetes mellitus: IDDM4, IDDM5 and IDDM8. Human molecular genetics, 1996. 5 (5): p. 693-698.
[47] Luo, D.-F., et al., Affected-sib-pair mapping of a novel susceptibility gene to insulin-dependent diabetes mellitus (IDDM8) on chromosome 6q25-q27. American journal of human genetics, 1995. 57 (4): p. 911.

[48] Saccucci, P., et al., Association between PTPN22 C1858T and type 1 diabetes: a replication in continental Italy. Tissue antigens, 2008. 71 (3): p. 234-237.

[49] Chelala, C., et al., PTPN22 R620W functional variant in type 1 diabetes and autoimmunity related traits. Diabetes, 2007. 56 (2): p. 522-526.

[50] Ghandil, P., et al., Crohn's disease associated CARD15 (NOD2) variants are not involved in the susceptibility to type 1 diabetes. Molecular genetics and metabolism, 2005. 86 (3): p. 379-383.

[51] Holm, P., et al., the European Consortium for IDDM Genetic Studies: A genome-wide scan for type 1 diabetes susceptibility genes in Scandinavian families: identification of new loci with evidence of interactions. Am J Hum Genet, 2001. 69: p. 13011313.

[52] Maine, C. J., et al., PTPN22 alters the development of regulatory $\mathrm{T}$ cells in the thymus. The Journal of Immunology, 2012. 188 (11): p. 5267-5275.

[53] Kissler, S., et al., In vivo RNA interference demonstrates a role for Nramp1 in modifying susceptibility to type 1 diabetes. Nature genetics, 2006. 38 (4): p. 479-483.

[54] Herold, M. J., et al., Inducible and reversible gene silencing by stable integration of an shRNA-encoding lentivirus in transgenic rats. Proceedings of the National Academy of Sciences, 2008. 105 (47): p. 18507-18512. 